\title{
Flow Characteristics of Multi-circular Jet Plate in Premix Chamber of Air-Assist Atomizer for Burner System
}

\author{
Shahrin Hisham Amirnordin ${ }^{1, *}$, Amir Khalid $^{1}$, Isma Adzrai Ismail ${ }^{1}$, Ronny Yii Shi Chin ${ }^{1}$, \\ and Mas Fawzi ${ }^{1}$ \\ ${ }^{1}$ Combustion Research Group, Centre for Energy and Industrial Environment Studies (CEIES), \\ Faculty of Mechanical and Manufacturing Engineering, Universiti Tun Hussein Onn Malaysia, Parit \\ Raja, 86400 Batu Pahat, Johor, Malaysia
}

\begin{abstract}
The flow characteristics of multi-circular jet (MCJ) plate in the premix chamber of an atomizer were investigated using Computational Fluid Dynamics. Multiphase volume of fluid behavior inside the chamber was determined via steady simulations. The Eulerian-Eulerian two-fluid approach was used for execution mixing of diesel fuel and air. Spray simulation using the discrete phase with injection was generated from the nozzle hole into the ambient atmosphere. The behavior of three MCJ plates in the premix chamber was studied numerically. Results illustrated that plate open area, $A_{e}$, influenced the turbulence inside the chamber. MCJ 3, which had the lowest open area, generated the highest flow velocity and turbulence kinetic energy compared with MCJ 1 and 2. The MCJ plates could increase the turbulence in the premix chamber and contribute to the combustion efficiency.
\end{abstract}

\section{Introduction}

In recent years, premix combustion technology has received particular attention in response to strict emission regulations introduced by the authorities. The reduction in emission, especially nitrogen oxides $\left(\mathrm{NO}_{\mathrm{x}}\right)$, can be observed when a conventional burner is replaced by a premix burner. The thermal efficiency of a premix burner system can also be optimized because of its capability to operate under very low excess air. In a premix burner, enhanced mixing between fuel and oxidizer can be achieved by the presence of a turbulence generator. Many techniques have been explored in generating turbulence, including the application of compact active grids [1], fractal grids [2-5], and multi-circular jet plates [6].

Among the turbulence generators, fractal grids have attracted much research because of their high fluid mixing efficiency. Theoretically, a fractal grid differs from a standard grid because it creates turbulence by exciting many length scales of various sizes simultaneously, rather than a single one. Krogstad [4] revealed the strong dependency of turbulence on the grid geometry. Soulopolous et al. [7] used the fractal grid to generate turbulence in the premixed flame. The results illustrated the advantages of a fractal grid,

\footnotetext{
*Corresponding author: shahrin@uthm.edu.my
} 
which created more intense turbulence and changed the combustion regime. Verbeek et al. [3] studied the fractal grid with the aim of increasing the turbulent and combustion rate in a low swirl burner. An increase in turbulence intensity was observed when the flow of the multi-grid was compared with the standard grid.

Other types of turbulence generators are multi-circular jet (MCJ) and non-circular jet plates. One of the earlier studies was conducted by Coppola and Gomez [6], who investigated the effects of geometric parameters on two families of high-blockage plates (i.e., circular and non-circular). Hot wire anemometry was used on the turbulent free jet with measured parameters of axial velocity, turbulence intensity, and turbulence length scale of corresponding Reynolds numbers. Several characteristics of the plates were identified for each group. In MCJ plate, the geometry was defined as the hole diameter, d; the radial position of the holes, $\mathrm{R}_{\mathrm{s}}$; the number of holes, $\mathrm{N}$; and the plate open area, $\% \mathrm{~A}_{\mathrm{e}}$ (i.e., the area of circular openings). The MCJ was observed to perform well in achieving a high turbulence level at a given flow rate and preserving radial uniformity. From the findings, the turbulence generation through high-blockage perforated plates was a viable way to generate intense turbulent field with certain precautions on instabilities because of the openings, shape, and position. However, the effects of the MCJ plates on the flow inside the premix chamber of the atomizer need to be investigated further to determine the influence on spray formation.

This study analyzed MCJ plates inside the premix chamber of an air-assisted atomizer using Computational Fluid Dynamics (CFD), which enables the detailed investigation of the fluid flow being conducted. Three different types of MCJ plates with different patterns and geometries were studied. The results were analyzed in terms of fluid flow in the premix chamber and the behavior of atomization nozzle, such as the velocity and turbulence kinetic energy.

The rest of the paper is organized as follows. The next section describes the numerical calculation, the boundary conditions, the physical model, and the meshing of the calculated domain. In the results and discussion, air flow structure, exit velocity profile, and turbulence kinetic energy are discussed. The last section explains the conclusion from the analysis of the results.

\section{Methodology}

Calculation methods. Calculations were performed using ANSYS Fluent commercial CFD software. The equation involved was the fully 3D, steady, compressible, Navier-Stokes equation. The solver used the implicit pressure-based algorithm. Two phases of fluid (diesel in liquid and air) were used in this work, which required the multiphase volume of fluid model. The turbulence model employed was the transition four-equation shear stress transport model. Discretization involved the PISO scheme with spatial discretization of the first-order upwind scheme. The calculation involved species transport using air as a primary phase and diesel liquid as a secondary phase.

Boundary conditions. The inlet air and inlet fuel used mass flow inlet conditions, which define the mass flow rate, flow direction, and angle. In this study, the air mass flow rate was fixed at $0.00393 \mathrm{~kg} / \mathrm{s}$, whereas the inlet fuel mass flow rate was set at $0.00026934 \mathrm{~kg} / \mathrm{s}$ [8]. The output flow was set at 1 bar, which is the standard atmospheric condition. The material of the solid wall was aluminum with the boundary of the wall for solid-fluid coupling, whereas the wall was specified as stationary wall motion (no slip condition). The discrete phase model was used for atomization characteristics with breakup as a physical model, and injection type was a solid cone with droplet particle. The effects between the droplet and flow were obtained from this model. 
Physical model and mesh. The position of the MCJ plate in the injector is illustrated in Fig. 1(a). The premix chamber was the location for fuel and air mixing before spraying through the nozzle holes out into the environment. It was $6.70 \mathrm{~mm}$ in radius and $35.66 \mathrm{~mm}$ in length, which resulted in a volume of $4098.15 \mathrm{~mm}^{3}$. The top of the chamber contained eight injector nozzles with $1 \mathrm{~mm}$ in diameter and $45^{\circ}$ angle. The geometric model of the domain is illustrated in Fig. 1(b).

Fig. 1(c) displays the mesh of the MCJ plate in the mixing chamber. The tetrahedral unstructured grids were employed because of the complexity of the structure. The grid independence study was conducted for three sets of number of elements (i.e., 187,669; 212,181; and 287,350). The maximum error for the velocity inside the exit nozzle of the local position was $1.05 \%$, and the relative errors in the remaining calculations were about $1 \%$. Therefore, the selected numerical scheme applied in this work was 212,181 elements. The actual physical appearance of the plates is described in Table 1, which shows the terms used in the plates; the percentage of a plate's open area with respect to the plate's total area, $\% A_{e}=100 \times\left(A_{e} / A_{p}\right)$, where $A_{p}$ is the plate's total area.

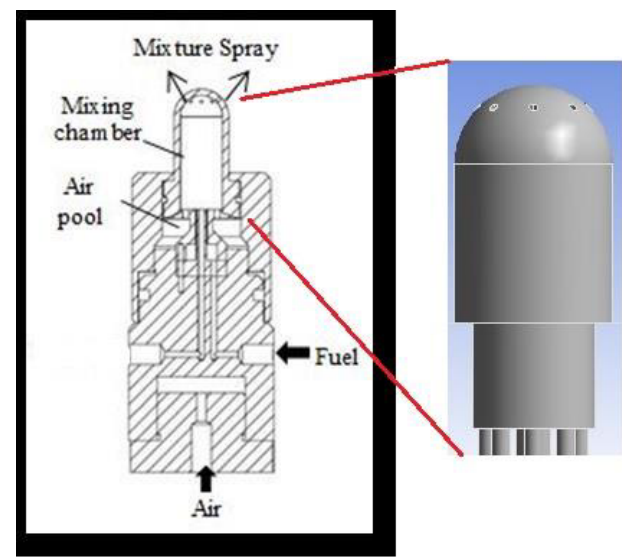

(a)

(b)

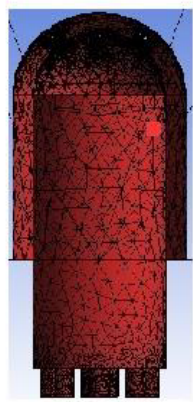

(c)

Fig. 1. The premix injector showing (a) the MCJ plate location (b) the geometrical model and (c) the meshing

Table 1. The geometry of (a) MCJ 1 (b) MCJ 2 (c) MCJ 3

\begin{tabular}{|c|c|}
\hline & \\
\hline
\end{tabular}




\section{Results and discussion}

Results of mixing chamber flow simulation. The flow of the mixture from the uniform grid (MCJ 1) is shown in Fig. 2. The streamline velocity from the fuel and air inlet (at the bottom) exited through the nozzle (at the top) of the injector. The figure indicates the development of velocity from the bottom part of the chamber (near inlet) before achieving its high velocity through the atomizing nozzles [8].

Fig. 3 exhibits the nozzle exit velocity profile of all the plates and the velocity across the chamber at the exit plane, with $30 \mathrm{~mm}$ downstream of the plate. The profiles showed that the flow was almost symmetric with three peaks of the velocity, and the central velocity was lower than its left and right peaks. This difference was due to the large opening of inlet fuel at the center of the chamber and lower mass flow rate compared with the air inlet at its peripheral [9]. At this location far from the inlet, the velocity was close to the bulk velocity in the chamber. MCJ 3 displayed the highest velocity compared with MCJ 1 and MCJ 2. This result was related to the open area, $\% \mathrm{~A}_{\mathrm{e}}$, which demonstrated that MCJ 3 had the lowest value of 10.03 compared with MCJ 1 (17.82) and MCJ 2 (13.92).

Fig. 4 represents the turbulence kinetic energy of mixing fluids along the premix chamber of the injector. The turbulence kinetic energy of all the plates increased toward its peak at $6 \mathrm{~mm}$ from the inlet; this value decreased and became constant before it sprayed out through the nozzle. Based on the graph, MCJ 3 flow inside the injector displayed the highest turbulence kinetic energy because of its low open area compared with MCJ 1 and MCJ 2.

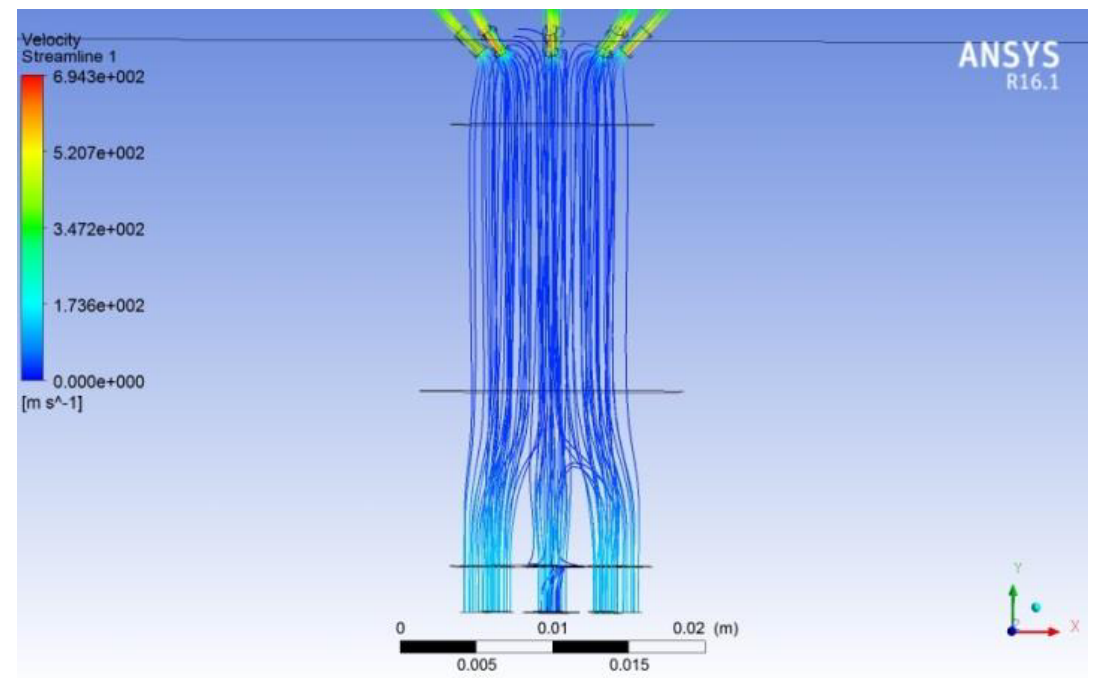

Fig. 2. The velocity streamlines of mixture from the inlet and exit through the nozzle of injector for MCJ1 


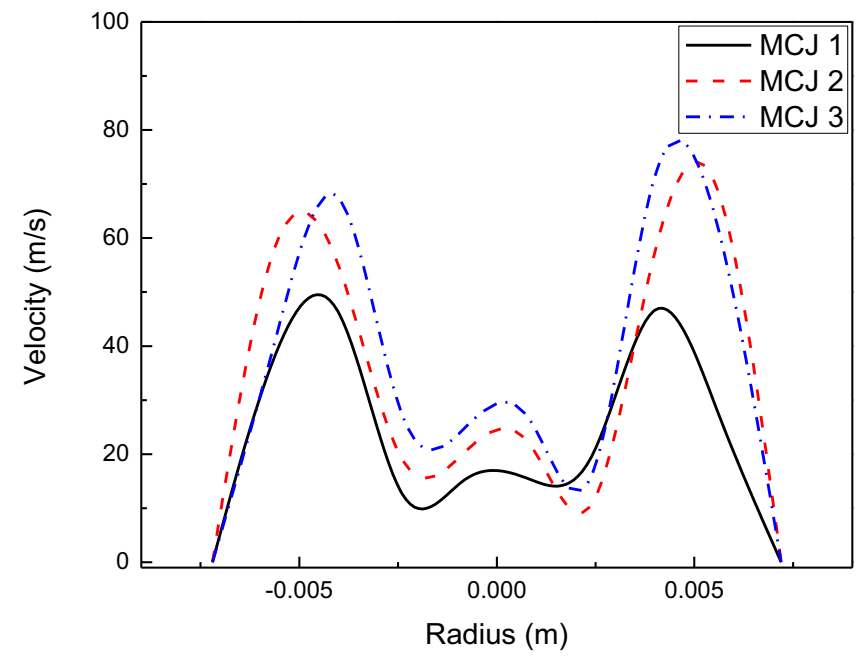

Fig. 3. The nozzle exit velocity profiles of all the plates

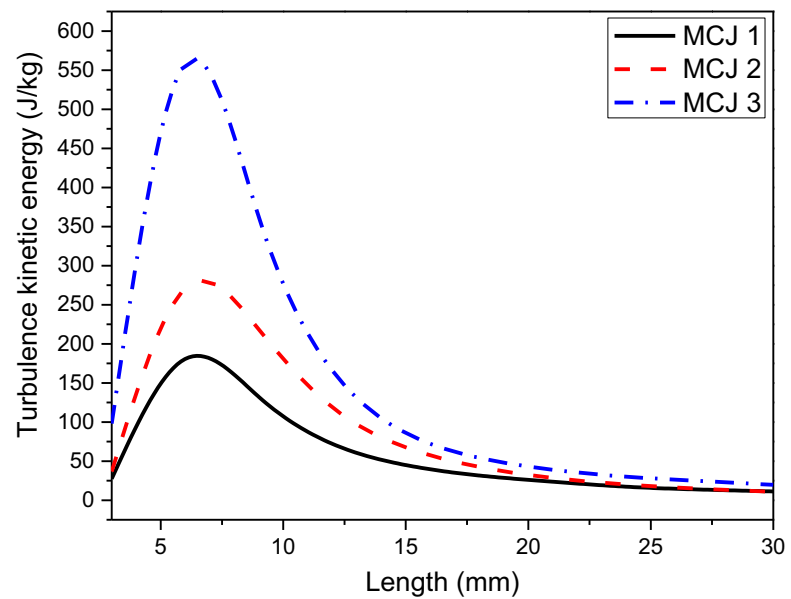

Fig. 4. The turbulence kinetic energy in the premix chamber

\section{Conclusion}

In this paper, the turbulence generated from MCJ plates was investigated numerically using ANSYS Fluent. Its influence on the flow behavior in the premix chamber of the atomizer was also studied. The flow characteristics were mainly influenced by the geometry of the MCJ plate. The open area, $\% \mathrm{~A}_{\mathrm{e}}$, significantly affected the turbulence, which could improve the mixing of fuel and air inside the premix chamber. Overall, MCJ 3 with $10.03 \% \mathrm{~A}_{\mathrm{e}}$ exhibited the highest performance among the three plates.

The authors would like to thank the Centre for Graduate Studies, Universiti Tun Hussein Onn Malaysia and Ministry of Higher Education, Malaysia, for supporting this research. 


\section{References}

1. A.A. Verbeek, Efficiently generated turbulence for an increased flame speed (University of Twente, Netherland, 2014)

2. R.E. Seoud, J. C. Vassilicos, Phys. Fluids., 19, 105108 (2007)

3. A.A. Verbeek, T.W.F.M. Bouten, G.G.M. Stoffels, B.J. Geurts, T.H. Meer, Combust. Flame, 162 (2015)

4. P. Krogstad, Int. J. Heat Fluid. Fl., 35 (2012)

5. H. Suzuki, K. Nagata, Y. Sakai, R. Ukai, Phys. Scripta, T142, 014069 (2010)

6. G. Coppola, A. Gomez, EXP. Therm. Fluid Sci., 3, 1037 (2009)

7. N. Soulopoulos, J. Kerl, F. Beyrau, Y. Hardalupas, A.M.K.P. Taylor, Fluid. Dyn., (2010)

8. R.Y.S. Chin, A. Khalid, A.M.A. Ghani, I.M. Mahad, S.H Amirnordin, (IRIS, Putrajaya, 2015)

9. N. Soulopolous, J. Kerl, T. Sponfeldner, F. Beyrau, Y. Hardalupas, A.M.K.P. Taylor, J. C. Vassilicos, Fluid. Dyn. Res., 45, 061404 (2013) 